\title{
Usability Evaluation Procedure for the Agricultural Equipments in Local Agricultural Task Environment
}

\author{
Woo Chang Cha \\ Department of Industrial Engineering, Kumoh National Institute of Technology, Gumi-City, Kyoungbuk, 730-701
}

\begin{abstract}
Objective: to improve agricultural working environment using tools and equipments. Background: most existing tools currently used, in fact, are discrepant from human factor guidelines so that they are still exposed to the musculoskeletal disease. Method: the provided tools and equipments are mostly designed considering human factor engineering or usability engineering in a way to avoid musculoskeletal disease. Results: propose the top-down procedure and usability engineering steps to evaluate them for the system design suitability. Conclusion: apply them conveniently into rural environment to help farmers working environment.
\end{abstract}

Keywords: Usability engineering, Human factor evaluation, Musculoskeletal disease

\section{Introduction}

한국 농촌의 작업 환경이 꾸준히 개선됨에 따라 농촌에서 사용되고 있는 농작업 편이장비에 대한 관심이 커지고 있다.

농작업 편이장비란 지역별, 작목별 특성에 맞는 농산물의 생산, 수확, 포장 등과 관련된 작업자세의 개선, 중량물 운반 작업의 개선, 작업능률의 향상, 특정신체부위에 의한 반복 및 과도한 힘이 필요한 작업의 개선을 위한 인간공학적 장비 를 말한다.

한국의 농촌 인구가 고령화되고 여성인력 비율이 지속적 으로 늘어나면서 노약자 농업인들에 대한 농작업 관련 문제 점의 개선 및 작업능률 향상을 목적으로 농작업 환경개선 편이장비 지원사업이 2008년 전국 39개 마을을 시작으로 진행되고 있다.

편이장비 사업의 일환으로 인간공학자를 중심으로 근골 격계 질환을 예방하기 위해 중량물 운반 편이장비를 중점적 으로 개선하고 있으나 편이장비 업체의 영세함과 농업인의 편이장비 도입에 대한 인식부족으로 인해 시행초기에 약간 의 혼란이 있음은 주지의 사실이다.
편이장비를 제한된 기간 내에 지역별, 작목별 특성에 맞게 개선하거나 개선된 장비를 적기에 구입하기 위해서는 농촌 특성에 맞는 편이장비 사용성 평가 방법에 대한 실용적 대안 이 필요하다. 본 논문은 이러한 편이장비에 대하여 농촌 환 경에 적절한 사용성 이해와 사용성 평가 방법에 대하여 개 괄적으로 기술하고 있다.

\section{Equipment Usability}

편이장비의 사용성 (usability) 문제는 왜 어떤 장비는 자주 사용되며 어떤 장비는 사용하지 않고 있는가에 대한 것이다. 사용성의 일반적인 평가 방법은 학습의 용이성(learnability), 사용의 효율성 (efficiency), 기억의 용이성 (memorability), 오류빈도(errors), 사용자 만족도(user satisfaction) 등이 있다. 초기 사용성에 대한 의미는 어떤 장비가 사용하기 편 리하다는 것을 의미했지만 시간이 지나면서 사용성이란 의 미를 보다 폭넓은 개념으로 이해하게 되었고 그 의미가 다 양하게 사용되어 왔다.

Corresponding Author: Woo Chang Cha. Department of Industrial Engineering, Kumoh National Institute of Technology, Gumi-City, Kyoungbuk, $730-701$. Mobile: 010-7143-8611, E-mail: chaw@kumoh.ac.kr

Copyright@2011 by Ergonomics Society of Korea(pISSN:1229-1684 eISSN:2093-8462). All right reserved. 
사용성에는 시스템을 효율성과 수행능력의 관점에서 보는 인지적 사용성 (cognitive engineering), 사용자가 시스템을 사용하고 난 후 기쁨과 만족, 좋은 인상을 가지는 사용자의 경험에서 본 경험적 사용성 (experiential usability) 혹은 사 용자 경험(user experience), 그리고 사회, 경제, 문화적 측 면에서의 사회적 사용성(social usability)이 있다. 시스템 의 사용성 평가에서 개념을 구체화하는 학문을 사용성 공학 (usability engineering)이라 부른다.

\subsection{Cognitive usability}

인지적 사용성 (cognitive usability)은 농작업 경험과 사회 적 능력에 기초한 인지적 능력을 고려하여 시스템 평가를 수행하므로 사용성 평가 중에 가장 중요하고 우선적으로 평 가되어야 한다. 사용장비에 대한 인지적 사용성의 평가기준 은 사용의 효율성, 학습의 용이성, 안전성, 기억의 용이성이 있다.

장비 사용의 효율성 (efficiency) - 사용자가 수행하는 일을 원활하게 잘 지원해 주고 있다는 것을 뜻한다. 편리하 다는 말도 효율적이라는 말과 비슷한 의미라고 할 수 있다.

장비 학습의 용이성(learnability) - 이는 주로 장비를 접한지 얼마 되지 않은 시기와 관련되어 있는 개념이다. 사 용법에 대해서는 쉽게 배울 수 있어야 한다.

장비의 안전성 (safety) - 장비 사용시 사용자의 안전에 어떤 영향을 미치는지 그 시스템요소에 대한 평가이다.

기억의 용이성 (memorability) - 시스템의 인터페이스가 얼마만큼 사용법을 기억해내는 데에 도움을 줄 수 있는지의 문제는 중요하다.

효율성이 장비 사용에 익숙한 사용자에 초점을 맞추고 있 다면 학습용이성은 장비 사용의 초보사용자에게, 기억의 용 이성은 보통의 사용자에게 초점이 맞추어 있다.

편이장비의 인지적 사용성은 장비를 처음 사용하는 비전 문 사용자를 위주로 설계되면 처음에는 효율성이 높지만 시 간이 경과하면 더 이상 효율성이 증가하지 않으므로(그림 1) 사용 방법에 익숙해지는 전문가 수준을 염두에 두고 장 비를 설계해야 한다.

\subsection{Experiencing Usability}

사용자에게 사용성을 증가시키는 것은 효율성이나 합리 성에만 있는 것이 아니라, 사용자 경험, 즉 경험적 사용성 (experiencing usability)을 강조한다.

사용하기 편한 것이 모든 것을 말하는 것은 아니다. 편이

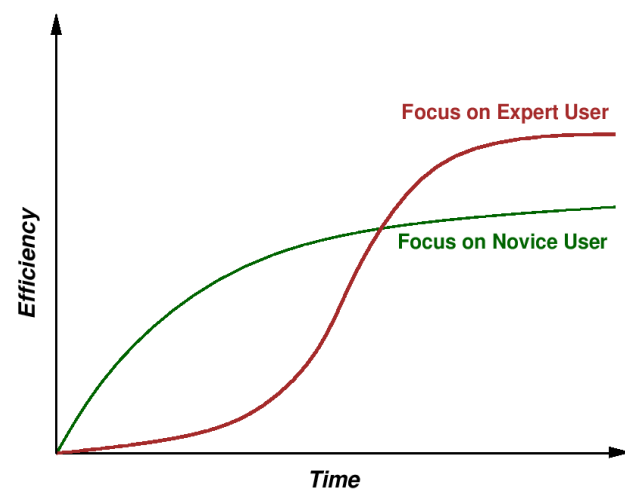

Figure 1. Usability efficiency for users' skill level

장비를 사용하면서 투박한 농작업 장비라 할지라도 심미적 인 기쁨과 즐겁고 의미가 있어야 한다. 동기가 부여되고 흥 미를 느낄 수 있어야 한다. 때로는 사용하기 어려운 시스템 이 도리어 도전감과 성취감을 줄 수도 있다. 경험하기 전에 갖는 합리적 사용성보다는 경험을 통해 느낄 수 있는 사용자 의 경험의 세계가 중요해지고 있다. 인지적 사용성이 아무리 좋아도 사용자의 독특한 농작업 경험에 기초하여 사용성을 평가하여야 한다.

\subsection{Social usability}

사회적 사용성(social usability)은 편이장비를 보급하 려는 국가적 정책에 부합한 가를 평가하는 정치적 사용성 (political usability) 과 사용장비가 현대 농촌 문화에 부합한 지를 다루는 문화적 사용성 (cultural usability), 그리고 제품 이미지 혹은 위상 정립(positioning), 마케팅, 가격 등 경제 적 요인에 의해 사람들이 시스템을 사용하기도 하고 그렇지 않기도 할 때 관여하는 경제적 사용성이다. 편이장비가 아무 리 우수해도 농업인 개인 환경에 과도하게 비싸거나 유지 비 용이 매우 높으면 편이장비 사용성을 떨어지게 된다.

\section{Usability Evaluation Procedure}

편이장비와 같은 인간기계시스템을 제작하거나 개선하기 위해서는 일반적으로 설계- 평가-구현 단계의 순환과정을 거친다. 장비의 기술이나 구체적인 성능, 사용자 환경 등을 깊이 모르고 장비를 제작하거나 개선하기 위해서는 순환과 정을 통한 시간이 많이 소요된다. 특히 평가 단계에서는 개 선된 평가장비의 설계자나 사용자 모두에게 인지적인 거리 (cognitive distance)가 크기 때문에 인지적 사용성 문제가 
대두되며 평가의 단계를 가급적 줄이는 평가 방법을 사용해 야 한다.

평가 단계를 개별 농촌 환경에 따라 분야별 전문가가 참여 하는 단계에서는 휴리스틱 평가를 수행하는 것이 합리적으 로 보인다. "휴리스틱 평가(heuristic evaluation)" 방법이 란, 닐슨(Nielsen, 1994)이 사용자 인터페이스를 평가 목 적으로 개념화시킨 방법으로, 전문가는 물론, 비전문 평가자 들이 휴리스틱, 즉 평가 가이드라인을 사용하여 시스템 인터 페이스의 약점이나 문제점을 파악할 수 있도록 돕는데 그 목적이 있었다.

휴리스틱 평가 단계. 계획 시에는 평가하고자 하는 시스템 에 대해, 평가자에게 시스템을 사용하여 어떤 일을 수행하 게 할 것인지를 결정하는 것(계획 단계)이 매우 중요하다. 평가자 결정 단계에서는, 누구를 평가자로 세울 것인지와 몇 명을 택할 것인지를 결정해야 한다. 일단 계획이 세워지 고 평가자가 결정되면, 실행을 하고 결과 분석이 이루어지게 된다. 분석 단계에서는 발견된 사용성의 문제를 의미 있게 분류해 보고, 가능하다면, 해결책을 제시한다.

평가자 결정. 몇 명의 평가자가 필요한가? 닐슨과 랜다우 르(Nielson\&Landauer, 1993)는 그들의 연구를 토대로 그 림 2에서 보여주는 그래프를 제시한 바 있다. 그래프를 보면, 5 명이 넘어가면서 새로운 사용성 문제가 발견되는 일이 급 격히 줄어드는 것을 알 수 있다. 따라서 그들에 의하면, 5 명 을 전후한 평가자의 수가 가장 효과적일 수 있다. 평가자 풀 에는 경험적 사용성을 고려하여 2 명 이상의 인간공학적 설 계의 취지를 이해하는 실제 농기게 사용자를 포함하는 것이 바람직하다.

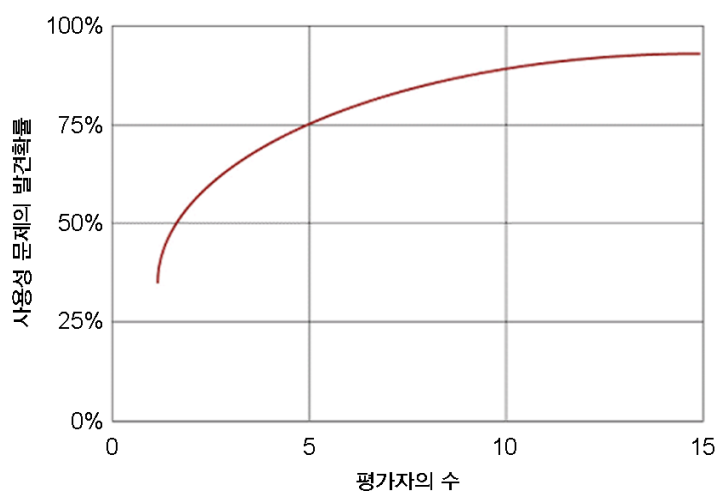

Figure 2. Number of evaluators for usability evaluation

계획을 세우고, 평가자를 정했으면, 평가자들에게 무엇 을 해야 할 지를 전하고 토의해야 한다. 이를 브리핑 세션 (briefing session)이라 부르기도 한다.
브리핑 세션이 지나면, 주어진 휴리스틱을 토대로 평가자 들이 시스템을 사용하면서 해야 할 작업들을 수행하고 평가 를 한다. 이러한 실행과정에서는 다음 두 방법 중 하나를 택 하게 된다.

개별 평가: 각 개인의 평가자가 각각 사용성을 평가하고 이를 정리하여 기획자에게 알려준다. 개별 평가는 그룹 평가 에 비해서 더 많은 사용성의 문제를 발견하는 데 유리하지만, 일반적으로 더 많은 시간이 소요된다.

그룹 평가: 평가는 하나의 팀으로 이루어진다. 모든 팀원 이 발견되고 논의된 문제에 대해서는 기획자에게 보고되어 야 한다. 그룹 평가는 팀이 하는 일이기 때문에 개별 평가에 비해 계획에 더 많은 시간이 필요하다.

평가 결과에 대한 분석 단계로서, 이를 디브리핑 세션 (debriefing session)이라고도 부르기도 한다. 평가자들이 모여서 결과에 대해서 의논할 수 있으면 매우 좋다. 이 경우, 분석은 대개 다음과 같은 단계를 거치면서 이루어진다.

- 중복된 평가는 줄이고, 비슷한 주제들은 같은 부류로 묶 는다.

- 문제 혹은 주제에 대한 우선순위를 정한다.

- 발견된 문제에 대해서 가능한 해결책을 제시한다.

결과 분석 특별히 기획자가 평가자들의 의견을 가지고 논 의를 하게 될 때, 그들의 의견에 대해 논쟁을 벌일 필요는 없다. 발견된 문제에 대한 어떤 설명을 하려고 애쓸 필요도 없다. 있는 그대로 받아들이면 된다. 일반적으로 평가자들에 게 발견된 문제들은 일반 사용자들이 사용할 때도 나타나는 문제들이다.

분석 결과 인지적 사용성, 경험적 사용성 및 사회적 사용 성 결함(deficiency)이 발생하면 인간공학적 사용성 결함 및 해결방안에 대하여 $\mathrm{HED}$ (Human Engineering Deficiency) 보고서를 작성하여 항목을 이슈화하고 해결가능 여부를 평 가자 그룹 및 장비업체와 토의 및 최종 조율을 거친다.

\section{Conclusion}

편이장비 사업이 농촌 지역별, 작목별 농작업 환경에 부합 한 편이장비를 제작 혹은 개선해서 노약자 농업인의 근골격 계 질환을 예방하고 농업인의 삶의 질을 향상하는 데 있다. 하지만 현재 한국 농촌의 현실은 영세한 장비업체와 농업인 의 편이장비 사용성에 대한 인식부족으로 인해 사업초기에 혼란이 있지만 개선된 장비를 사용 후 장비업체나 농업인 모두에게 긍정적으로 평가가 될 것이다.

본 논문에서는 편이장비에 대한 인간공학적 설계나 평가 
가 어려운 환경에서 편이장비의 사용성 평가를 개괄적으로 하는 방법과 절차를 기술하였다. 인간공학적 평가항목에 대 한 구체적인 반영보다는 기존장비에 대한 사용성 평가를 체 계화해서 농작업 환경에 대한 농업인들의 인간공학적 필요 성을 고취하는 것이 시급하다. 이에 따라 편이장비 사용성 평가작업을 통한 지속적인 편이장비 개선작업이 필요하며 사용성 평가 항목에 대한 구체적인 연구도 병행되어야 할 것 이다.

\section{Acknowledgements}

This paper was supported by Research Fund, Kumoh National Institute of Technology.

\section{References}

Nielson, J., Heuristic evaluation, "Usability Inspection Methods," John
Wiely and Sons, pp 25-62. 1994.

Nielson, J. and Landauer, T. K., "A mathematical model of the finding of usability problems," Proceedings ACM/IFIP 93 Conference, The Netherland, April 24-29). 1993.

\section{Author listings}

Woo Chang Cha: chaw@kumoh.ac.kr

Highest degree: $\mathrm{PhD}$, Department of Industrial Engineering, Oregon State University

Position title: Professor, Department of Industrial Engineering, the Kumoh National Institute of Technology

Areas of interest: Cognitive Systems Engineering, Human Factors in Nuclear Power Plant, HRA

Date Received : 2011-06-30

Date Revised :2011-07-26

Date Accepted : 2011-07-26 